\title{
ELECTROMYOGRAPHIC DIAGNOSIS OF THE CARPAL TUNNEL SYNDROME
}

\author{
R. TOYONAGA \\ C. R. DEFARIA
}

Reduced sensory conduction velocity of median nerve fibres in the carpal tunnel is the earliest electrophysiological evidence of the carpal tunnel syndrome. However, in the early carpal tunnel syndrome, the values obtained by conventional methods involving measurement of velocity between digit and wrist, may not show any significant reduction.

Buchthal and Rosenfalck (1971) and Buchthal, Rosenfalck and Trojaborg (1974) measured the conduction velocities from digit to palm, palm to wrist and wrist to elbow. Their findings showed severe slowing from palm to wrist in the patients with the carpal tunnel syndrome, whereas the velocity from digit to palm showed only slight slowing. They suggested that exclusion of the normal segment of the median nerve, distal to the flexor retinaculum, made it possible to demonstrate abnormalities across the flexor retinaculum in the early carpal tunnel syndrome. Present investigations were undertaken to simplify their method, using surface electrodes instead of needles for routine investigation.

\section{METHODS}

Twenty five normal subjects, 5 males and 20 females, 16 to 57 years old (mean 38.1) were studied. They had no signs or symptoms of neuromuscular diseases. An additional 6 women, aged 49 to 55 , had volunteered for a normal control study. Specific inquiries did not reveal any evidence of neuromuscular involvement. However, their conduction velocities from digit to wrist did show slight reductions. Hence these people will be discussed later under the subclinical carpal tunnel syndrome.

The stimulus current consist of rectangular pulses, 0.05 to 0.1 milliseconds in duraction, delivered by a Devices Ltd. type 3072 stimulator. The stimulus was gradually increased until the response became maximum. Special attention was made not to give a supramaximal stimulation, so as to avold proximal displacement of the effective point of nerve excitation. The stimulating electrodes were a pair of clips. The cathode was placed at the distal phalanx of the thumb, and at the middle phalanx of the index, middle and ring fingers. The anode was placed 10 to 20 millimeters distal to the cathode.

The recording electrodes were a pair of silver disc electrodes mounted $2.8 \mathrm{~cm}$ apart in a Plexiglass holder. When recorded from the palm, the stigmatic electrode was placed on the palm, well outside the flexor retinaculum. When recording from the wrist, the electrode was placed proximal to the flexor skin crease. The ground

Department Of Medicine (Neurology), McMaster University Medical Center, 1200 Main Street Weat, Hamilton, Ontario, Canada: 
electrode was placed between stimulating and recording electrodes. Sensory responses were displayed on a Hewlett-Packard variable persistence oscilloscope, model 141B. When it was necessary, impulses were fed into an averager (Hewlett-Packard 5488A) and displayed on a memory/display oscilloscope (Hewlett-Packard 5480B).

The latency was measured from the onset of the. stimulus artifact to the initial positive peak and the amplitude was measured from peak-to-peak. The shortest distance was measured between the cathode and the stigmatic electrode (digit to palm). Similarly the distances between the digit and wrist and across the wrist were measured as the shortest distances between two stigmatic electrodes. The skin temperature was controlled between 31 and $35 \circ \mathrm{C}$ during examination.

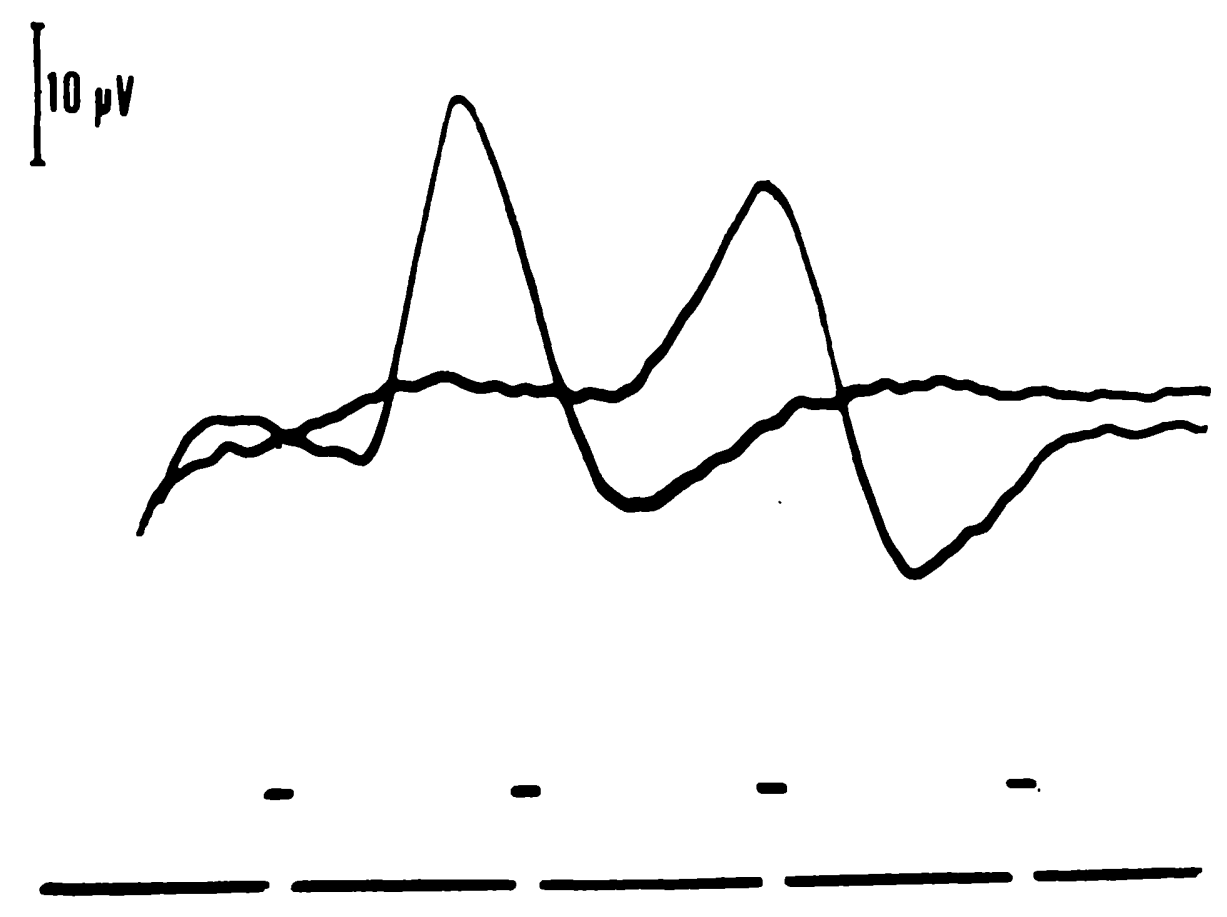

Frig. 1 - The recording of the evoleed potentials at the palm ard wrist. In the median nerve to middle finger.

\section{RESULTS}

Because of the large variation of normal values, the amplitude of sensory responses will not be discussed. The conduction velocities will be considered for each group.

1. Normal subjects - The results are summarized in Fig. 2. The maximum conduction velocity was the same in the segments between digit to palm, palm to wrist and digit to wrist in the index and middle fingers. The velocity of digit to palm in the thumb was the same as palm to wrist. However, it was reduced in the digit to wrist segments. This reduction is partly attributed to an error due to inaccurate measurement of distances on the surface (Buchthal and Rosenfalck, 1971). Also, the distance between the cathode and stigmatic electrode was so short (usually around $6 \mathrm{~cm}$ ) that the exact take-off point of the response was obscured by stimulus artifact. On the ring finger, the conduction velocity across the wrist was slower than in the other segments. The reason for this was not clear, but it may be that the corresponding fasciculus is especially susceptible to compression within the nerve trunk at the wrist.

2. Patients with the carpal tunnel syndrome. The results are summarized in Fig. 2.

Thumb - 30 median nerves were studied and sensory responses were recorded from the wrist in 28 of these. However, no satisfactory responses were recorded in 13 nerves at the palm and in 2 nerves both at the palm and the wrist. In most of these cases, the responses at the palm were obscured by stimulus artifact. In general, 


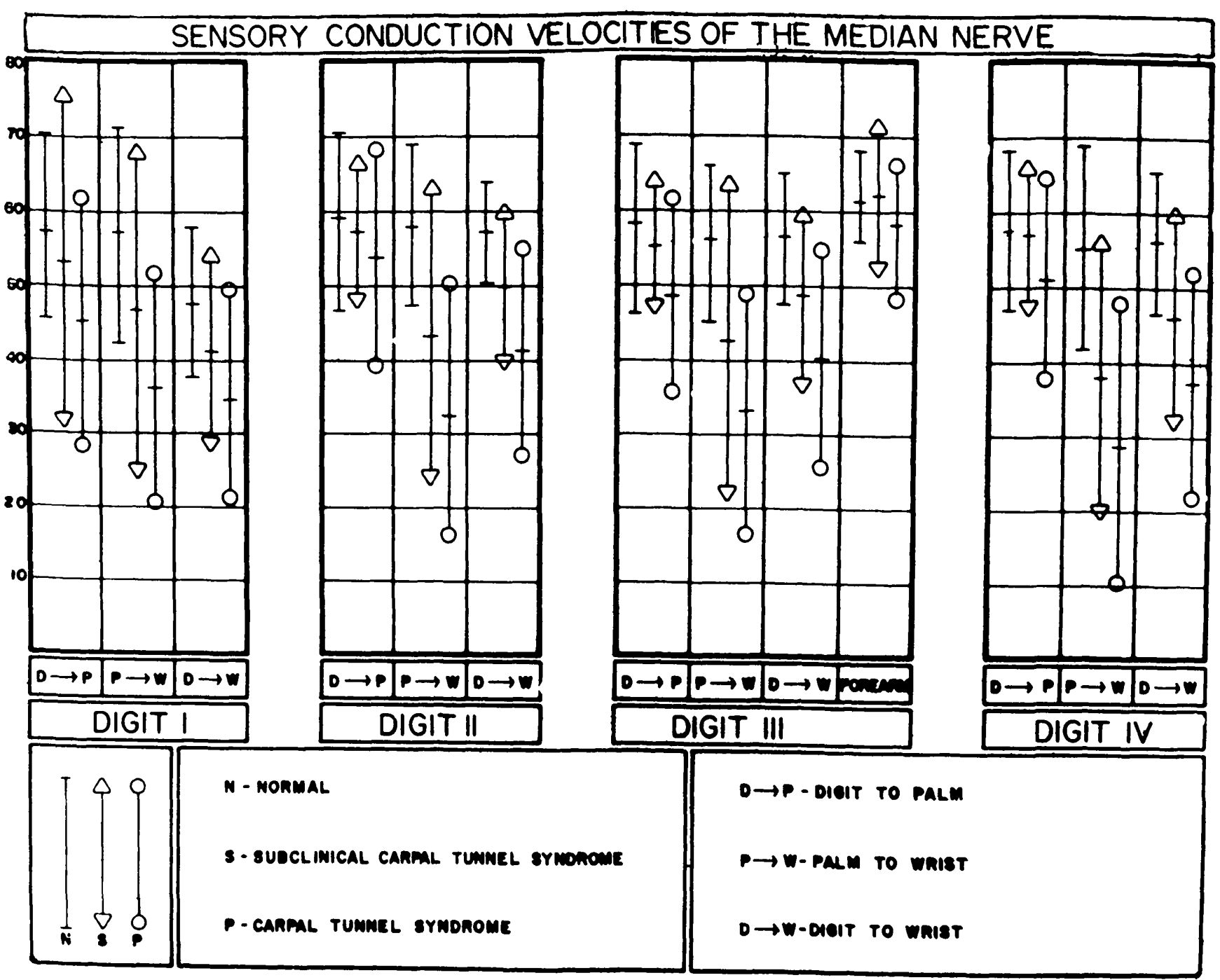

ERg. 8

stimulus artifact was bigger in the patients because stronger current was necessary to excite affected nerve fibres. For this reason, it was felt that the thumb was not a suitable finger if recording were to be made from the palm. Conduction velocities to the wrist were reduced in 18 nerves, but were within lower limits of normal or slightly reduced in the other 7 nerves. However, in all these 7 nerves, the conduction velocities were significantly reduced across the wrist, thus suggesting the presence of the carpal tunnel syndrome.

Index finger - 30 nerves weres studied (Fig. 2). In only one nerve it was impossible to record evoked responses from the palm or the wrist for technical reasons. The conduction velocities from digit to wrist were reduced in 16 nerves, in all these nerves, the velocities were markedly reduced across the wrist. In the remaining 13 nerves in which the velocities to the wrist were normal, $\theta$ had reduced velocities across the wrist. Therefore, in 25 out of 29 nerves the velocities across the wrist were reduced, thereby establishing a diagnosis of carpal tunnel syndrome.

Middle finger - An evoked response was absent at the palm in one nerve. The velocities from digit to wrist were reduced in 21 nerves and the velocities across the wrist were alsa reduced. Conduction velocities trom digit to wrist were normal in 9 nerves in which 8 nerve velocities were reduced across the wrist. Therefore 29 nerves out of 30 were abnormal.

Ring finger - 30 nerves were studied (Fig. 2) No responses were recorded from the wrist in two nerves and from both wrist and palm in one nerve. Conduction velocities to the wrist were reduced in 21 nerves in which velocities across the wrist 
were reduced in the same time. In the remaining 6 nerves, the velocities across the wrist were reduced in 4 . Therefore, 28 nerves out 30 were abnormal. The ring finger is innervated by the ulnar nerve as well. Therefore, it was difficult to be sure that the response recorded at the palm was from the median nerve. Slight displacement of the recording electrodes towards the radial side often reduced the influence from the ulnar nerve.

Frorearm conduction velocity - Of the 19 nerves measured, 13 nerves were normal and 6 were reduced.

3. Subclinical carpal tunnel syndrome. The results are summarized in Fig. 1. The conduction velocities from digit to wrist were normal or slightly reduced. However, conduction velocities across the wrist were significantly reduced in these cases; abnormal findings being seen on both sides in 4 persons and on the right side only in 2 . The lower values across the wrist found in these subjects involved the ring fingers in 7 instances and the thumb in 3 ; the middle and index finger were each affected once.

\section{DISCUSSION}

In the carpal tunnel syndrome, the initial changes are seen in sensory nerve fibres. In most of the mild cases, there is no prolongation of the distal motor latency and electromyography of median-innervated muscle is normal.

The determination of the conduction velocities from the digits to the palm (Fig. 3) and from the palm to the wrist (Fig. 4) has made it possible to identify slowed conduction along the median nerve in patients in whom conventionally recorded sensory and motor latencies were normal (Buchthal and Rosenfalck, 1971). Wiederholt (1970) has also measured the sensory conduction velocities of the median nerve across the carpal tunnel and above the wrist using surface recording electrodes. He suggested clinical use of this method for detections of the carpal tunnel syndrome. Buchthal, Rosenfalck and Trojaborg (1974), using needle recording electrodes, measured the velocities of the nerve in the thumb and middle finger from digit to palm, palm to wrist, and wrist to elbow.

In the mild carpal tunnel syndrome, the conduction velocities to the wrist measured by conventional method were only slightly reduced. whereas the velocities across the wrist were significantly reduced. Thus, by excluding the normal segment of nerve, it is possible to demonstrate an early carpal tunnel syndrome. Although there are several disadvantages in using surface electrodes for recording, the results obtained appear adequate for clinical use and the technique is more readily accepted by patients.

From this study it is likely that all digital branches of the median nerve were affected at the same time, but to different degrees; the fibres to the thumb and ring finger seem the most severely affected. A similar difference in susceptibility was seen in patients with subclinical carpal tunnel syndrome. The cutaneous branches of the median nerve supplying the thumb are aggregated in a funiculus separated from the branches to the other fingers (Johnson and Shrewsbury, 1970) and therefore, the thumb may be affected independently. In most of the patients of Buchthal and Rosenfalck (1971) conduction velocities obtained from the thumb were as abnormal as those from the middle finger. 

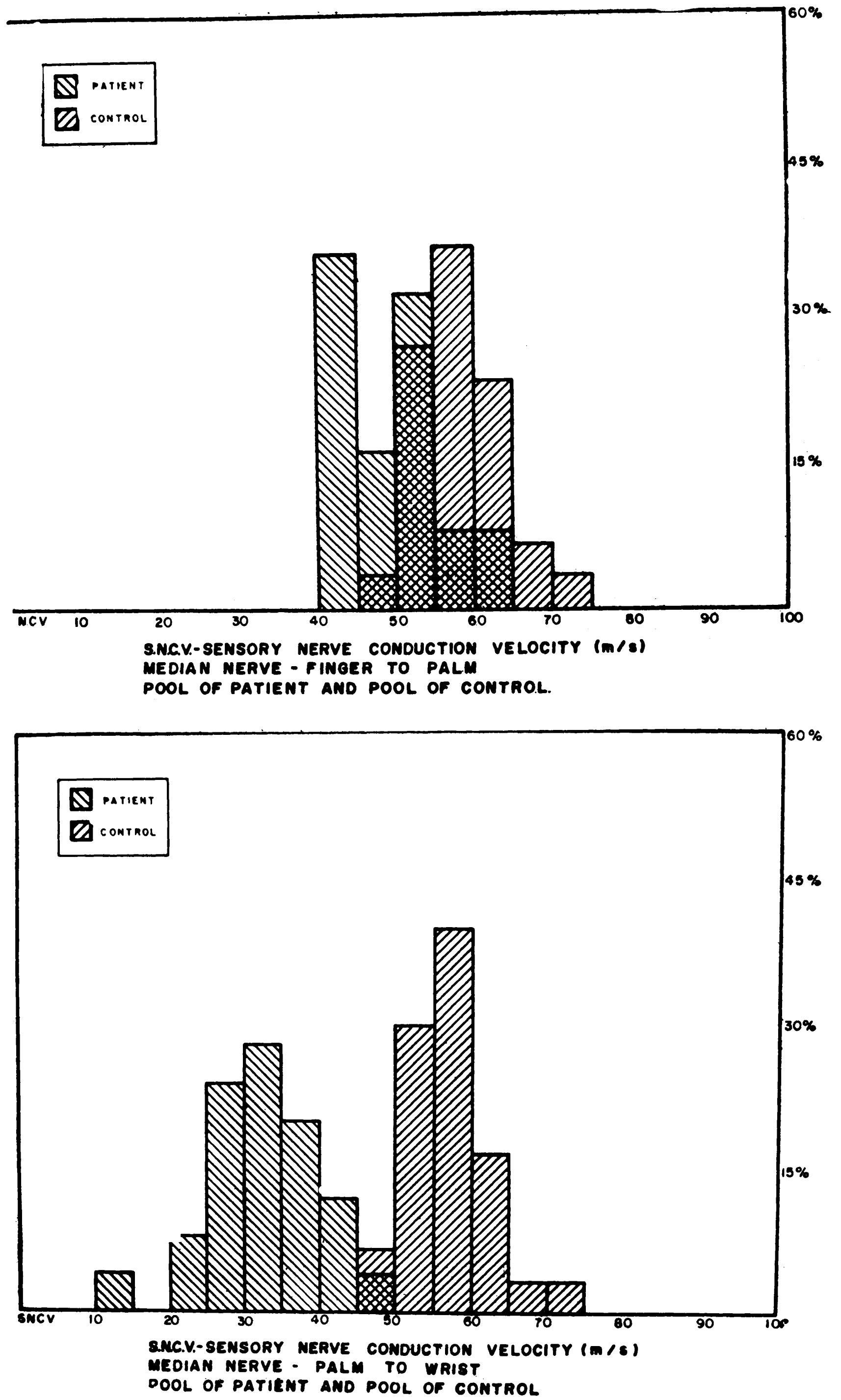

Figs. 3 and 4 - Conduction velocities at the median norve: distribution of 30 patients. 
However, in $10 \%$ of the patients, slowing was confined to either thumb or middle finger. If the thumb is not included to the investigation the sensitivity may be reduced slightly; because of technical difficulties it is advisable to study at least two fingers, preferably the ring finger and either the index or middle fingers.

An interesting observation was the presence of significant number of subclinical, but electrophysiologically-evident, carpal tunnel syndromes. The subjects were all females, aged 49 to 55 , without any signs or symptoms of median nerve compression. The reasons for the high incidence of the disoders in the present study are not clear.

It is a common observation to see abnormal electrophysiological findings on both sides in patients with the carpal tunnel syndrome, whose symptoms were restricted to one side. Similar observations were mentioned by Payan (1969) who investigated patients with cubital tunnel syndromes and found several abnormal sensory conduction velocities in the clinically unaffected side. Sedal et al (1973) studied ulnar nerve lesions associated with the carpal tunnel syndrome. They found abnormal ulnar nerve sensory potentials in $39.3 \%$ of the cases and interpreted this as an evidence of a co-existing peneralized subclinical neuropahty. Neary, Ochoa and Gilliat (1975) studied 12 persons at post-mortem, aged 36 to 84; none had any previous medical or neurological disorders which might have affected the peripheral nervous system. Twelve median nerves at the carpal tunnel and 12 ulnar nerves at the cubital tunnel were removed and were investigated using a teased fibre method. The authors found alterations of the internodes, which was the earliest change to occur in nerve fibres subjected to chronic or recurrent compression; this change sometimes progressed to demyelination. In addition to this, Neary et al found enlargement of nerve cross-sectional area due to an increase in connective tissue elements and presence of Renaut bodies (Asbury, 1973). They considered these changes as valid evidence of subclinical entrapment in apparently unaffected human subjects.

The pathogenesis of the carpal tunnel syndrome is still not well established. Associated conditions or diseases were cited by Phalen (1966) and Cseuz et al (1966). Also it is well know that the incidence increases with age with about 60 to $80 \%$ of patients between 40 and 60 years of age. This range coincides with the age distribution of our subclinical carpal tunnel syndrome population and Nearys patients with median nerve compression. From these observations, it is possible to speculate that with ageing, significant number of people, particularly females, develop subclinical carpal tunnel syndrome. However, due to safety factors (McComas et al, 1971) these people do not develop clinical manifestations. If they receive further damage to the nerve, then this safety margin is exceeded and clinical symptoms will ensue (Upton et al, 1973).

It will be most interesting to follow up these subjects to see if they develop overt clinical symptoms and what will be the major contributing factors. 


\section{SUMMARY}

Sensory conduction velocities of the median nerve were studied from digit to palm and from palm to wrist in normal subjects and in patients with the carpal tunnel syndrome. Definite slowing was noted in the palm to wrist segment, even in the early carpal tunnel syndrome. It was noted that $37 \%$ of normal women over 40 years of age had electrophysiological evidence of the carpal tunnel syndrome.

\section{RESUMO}

\section{Diagnóstico eletromiográfico da sindrome do tunel carpiano}

Velocidades de condução de fibras sensitivas do nervo mediano foram estudadas dos dedos à palma e da palma ao punho, em individuos normais e portadores de síndrome do tunel carpiano. Diminuição da velocidade foi observada no segmento da palma ao punho, mesmo em fases bastante precoces da sindrome. Encontrou-se também que $37 \%$ de mulheres clinicamente normais (acima de 40 anos de idade) tinham evidência eletrofisiológica de síndrome do tunel carpiano.

\section{REFERENCES}

1. ASBURY, A. K. - Renaut bodies, a forgotten endoneurial structure. J. Neuropathol. Exper. Neurol. 32:334, 1973.

2. BUCHTHAL, F. \& ROSFNFALCK, A. - Sensory conduction from digit to palm and from palm to wrist in the carpal tunnel syndrome. J. Neurol. Neurosurg. Psychiat. 34:243, 1971.

3. BUCHTHAL, F.; ROSENFALCK, A. \& TROJABORG, W. - Electrophysiological findings in entrapment of the median nerve at wrist and elbow. J. Neurol. Neurosurg. Psychiat. 37:340, 1974.

4. CSEUZ, K. A.; THOMAS, J. E.; LAMBERT, E. H.; GRAFTON LOVE, J. \& LIPSCOMB, P. R. - Long-term results of operation for carpal tunnel syndrome Mayo Clinic Proc., 41:232, 1966.

5. JOHNSON, R. K. \& SHRHWSBURY, M. M. - Anatomical course of the thenar branch of the median nerve, usually in a separate tunnel through the transverse carpal ligament. J. Bone Joint Surg. 52-A:269, 1970.

6. McCOMAS, A. J.; SICA, R. E. P.; CAMPBELL, M. J. \& UPTON, A. R. M. Functional compensation in partially denervated muscles. J. Neurol. Neurosurg. Psychiat. 34:453, 1971.

7. NEARY, D.; OCHOA, J. \& GILLIATT, R. W. - subclinical entrapment neuropathy in man. J. Neurol. Sciences. $24: 283,1975$.

8. PAYAN, J.-Electrophysiological localization of ulnar nerve lesion. J. Neurol. Neurosurg. Psychiat. 32:208, 1969.

9. PHAlew, G. S. - The carpal tunnel syndrome. J. Bone Joint Surg. 48-A:211, 1966. 
134 ARQ. NEURO-PSIQUiATRIA (SAO PAULO) VOL. 36, Nค 2, JUNHO, 1978

10. SEDAL, L.; MCLEOD, J. G. \& WALSH, J. C. - Ulnar nerve lesions associated with the carpal tunnel syndrome. J. Neurol. Neurosurg. Psychiat. 36:118, 1973.

11. UPTON, A. R. M. \& McCOMAS, A. J. - The double crush in nerve entrapment syndromes. Lancet 2:359, 1973.

12. WIEDERHOLT, W. C. - Median nerve conduction velocity in sensory fibers through carpal tunnel. Arch. Physical Med. Rehabilit. 51:328, 1970.

Author's present address:

Dr. K. Toyonaga - Okinowa Central Hospital - 198 Miyasato Gushikawa Okinawa - Japan.

Dr. C. R. DeFaria - Instituto de Neurologia de Goiania - Caixa Postal 15y 74000 Goiania, GO - Brazil. 